\title{
INTRA-OCULAR CYSTICERCUS
}

\author{
BY
}

D. J. WOOD

CAPE TOWN

THIS, like hydatid cysts of the orbit, is much more common in South Africa than in England. Six cases have come through my hands. The first two were in the vitreous, and one of these was shown to several ophthalmic surgeons in London for me by the late Mr. Nettleship. The second was sketched by Mr. Donald Gunn, and in both of these the head and suckers could be clearly seen. The third case, a very early one with the parasite just over the yellow spot, and only a little larger than the width of the disc, came once only and was lost sight of. The fourth, an excised eye,

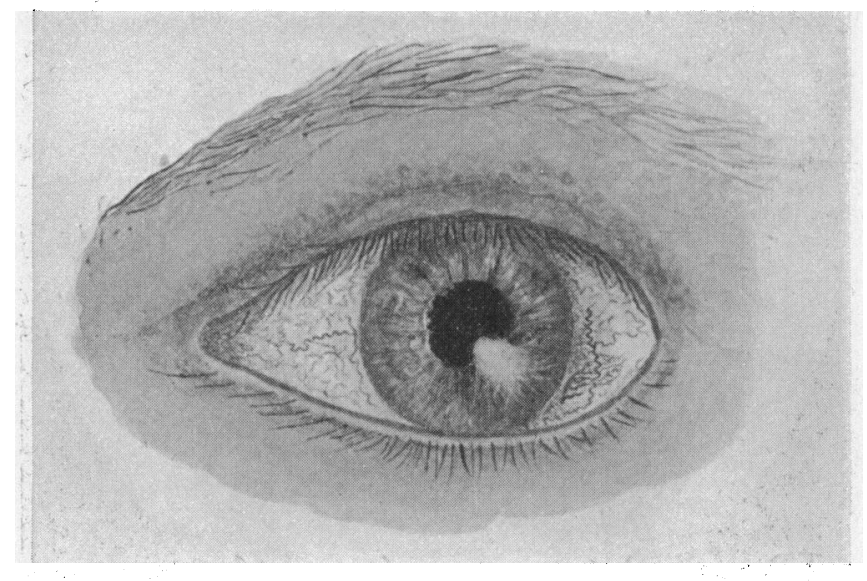

FIG. 1.

is in the Royal London Ophthalmic Hospital museum. A few remarks on the other two cases may be interesting.

1. The patient was a druggist and in a small way a farmer, and came to me for pain in the left eye of three weeks' duration, much more severe for four days. On the lower outer part of the iris there was a very definite cystic body, white in the centre and projecting into the pupil. It was fixed to the iris by numerous fine threads like spider-web or cotton wool. There was severe iritis and much pain and photophobia. Atropin produced no effect, and after a few days it was clear that the cyst was larger. No movements could be detected, but observation was difficult owing to the great photophobia. Under an anaesthetic I tried to remove the cyst with its bit of iris, but at the first touch of the 
forceps the cyst ruptured into the anterior chamber. Fragments were removed, but the threads were elastic and held to the iris. No hooklets were found in the débris, but the threads were examined and appeared to be hyaline, with cells at intervals. The sketch gives a fair idea of the appearance, and the micro-photograph of the threads. There was immediate relief from pain, but the pupil was largely occluded by lymph when the patient left.

2. The remaining case $I$ saw in 1903 . Patient (R. H. T.) came with a history of failure of vision in the left eye for three

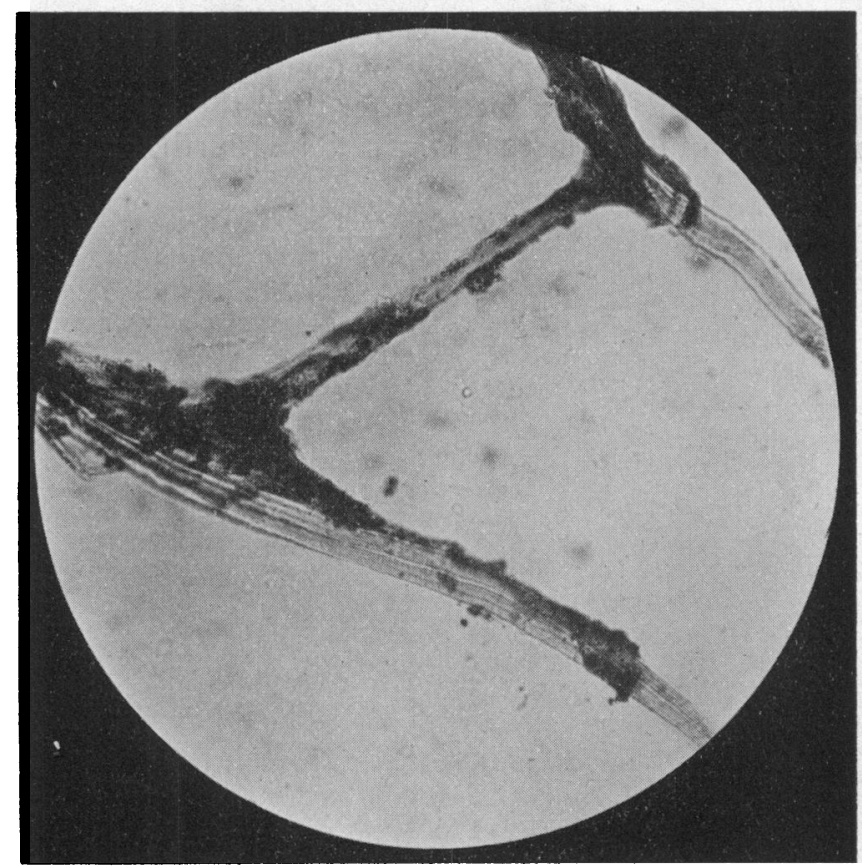

Fig. 2.

months beginning with flashes of light. The right had been failing for three days. The left eye had still $6 / 12$, but the right had only eccentric vision. No causal history could be obtained.

There was to be seen in the left eye a streak of serpiginous disturbance of the choroid, passing upwards from the disc. No visible detachment, but much vitreous dust. In the right eye were several recent spots of choroiditis, and on the inner side a large detachment. I formed no opinion of the nature of the case, and the patient disappeared for over two months. When I saw. him again the left eye was blind from extensive detachment. The light helped him to grope about. He was put to bed and after 
two weeks, performed paracentesis in each eye, and removed from beneath the retinae a fair amount of straw-coloured fluid. The right eye improved and one could see the puncture mark with the ophthalmoscope. The left remained blind, with complete detachment. About this time he developed a febrile illness, and was taken into hospital. It was not typical of anything, and was supposed to be a form of typhoid. After this he went home to England, and I heard to my surprise that both eyes had been excised for pain, one at Moorfields, the other at Guy's Hospital, and the remains of a cysticercus found. The attack of fever was probably a cysticercus fever, but from first to last there was no sign suggestive of cysticercus, though, of course, the bilateral affection would tend to put one off the track.

I have since found the report made on this case at Moorfields Hospital (p. 514, No. 6814 I.P.), which throws much doubt on the cysticercus theory. There had been severe choroido-retinitis, with organization of the subretinal exudate. There is a large space near the papilla, and one near the ora serrata which are filled with fibrin, and may have been cysticercus cysts, but there is nothing diagnostic about them. The retina is partly detached, but is mainly adherent to the surface of the newly-formed tissue.

I have not seen the report on the other eye.

\section{ANNOTATION}

\section{LIGHTING IN FACTORIES AND WORKSHOPS}

THE Departmental Committee on lighting in factories and workshops have now issued their third report. We greatly regret to note that owing to the urgent need for economy the present report is the final one, and we share the Committee's hope that further work on this most important subject may be resumed at a later date. As the Committee have included in this final report the recommendations made in the two previous reports, we have decided, in view of the great importance of the subject, to publish the part of the report embodying these recommendations in full. In addition to this part of the report, there are five valuable appendices which should prove of great assistance in pointing out to future workers on the subject fruitful lines of experiment. The first appendix gives a classification of the nature of the work in thirty-two different industries as regards " fine work " and " very fine work." The second appendix deals with observations on artificial light in spinning and weaving, and incidental processes 